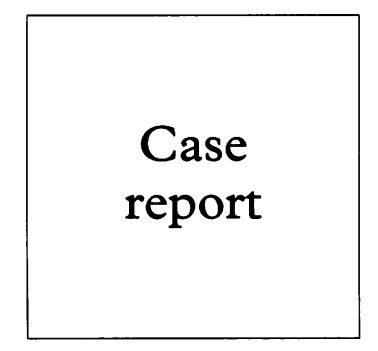

\title{
Condylomata acuminata of the penis progressing rapidly to invasive squamous cell carcinoma
}

\author{
Cornelus J G Sanders
}

\section{Introduction}

Condylomata acuminata are caused by human papilloma virus (HPV) infections and epidemiological and molecular-biological evidence points to an association between HPV infection and anogenital dysplasia. ${ }^{1}$ Human immunodeficiency virus (HIV) infection has been implicated as a promoting factor. ${ }^{2}$

In Zimbabwe the National Cancer Registry reports cervical carcinoma as the most common malignancy and recently an increase in reported squamous cell carcinoma of the penis has been observed, from one case per annum in 1993 and 1994 to six cases in 1995 and five cases in $1996 .^{3}$

I report here a patient with AIDS who rapidly developed squamous cell carcinoma of the penis in conjunction with longstanding condylomata acuminata.

\section{Case report}

A man, 32 years of age, presented with "genital warts" of more than 2 years' duration and a penile ulcer present for about 3 months, which showed no tendency to heal despite treatment for syphilis and chancroid. He complained of chronic diarrhoea and mentioned treatment for pulmonary tuberculosis which he had completed 2 years before presentation.

On examination the patient was a cachectic man with widespread seborrhoeic dermatitis, oral candida infection, and generalised lymphadenopathy. The penis showed typical exophytic condylomata acuminata on the

\footnotetext{
City of Bulawayo, Health Services Department, PO Box 1946, Bulawayo, Zimbabwe C J G Sanders Accepted for publication 29 May 1997
}

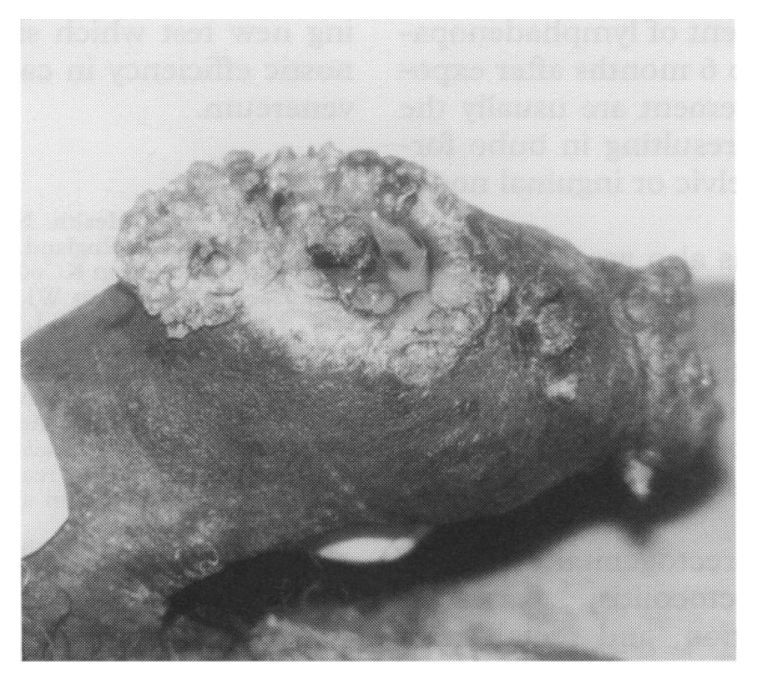

Condylomata acuminata and squamous cell carcinoma of the penis. phimotic foreskin and on the penis shaft. The $\frac{\bar{C}}{0}$ condylomata on the shaft were arranged $\frac{\bar{c}}{2}$ around a necrotic ulcer. Several hyperpig- $\overparen{\varnothing}$ mented flat condylomata were also present on the penis shaft (fig). In the left inguinal region? hard, non-mobile, lymph nodes were palpated.

A biopsy of the penile verrucous lesions and $\vec{\omega}$ ulcer and of an inguinal lymph node was taken. After pretest counselling the patient=consented to an HIV antibody test.

The biopsy specimen showed acanthosis or (increased thickness of the stratum Malpighii) $\stackrel{\circ}{N}$ of the epidermis with elongation of the rete을 ridges. Slight parakeratosis (incomplete keratinisation) was present. There was an increased number of cells with hyperchromatic nuclei and perinuclear vacuolisation in the upper and middle epidermis. The basal cell $\vec{\bullet}$ layer was intact and some mitoses were seen in the suprabasal layers. This process extended into the observed ulcer where irregular masses of pleomorphic and anaplastic epidermal cells proliferated downwards. The cells showed variation in size with hyperchromatic nuclei $\frac{\circ}{\Phi}$ and some atypical mitotic figures. Only a few $\overrightarrow{\vec{F}}$ horn pearls or individual cell keratinisation $\frac{3}{3}$ were observed. A chronic inflammatory cell infiltrate was present consisting of many? plasma cells, lymphocytes, and few eosinophilic leucocytes.

The inguinal lymph node showed destruc- $-\frac{3}{8}$ tion of the normal architecture with invasiono of atypical epithelial cells with hyperchromatic nuclei.

The HIV ELISA test (Abbott Diagnostics) $\frac{?}{2}$ was reported as positive. The rapid plasma reagin test (Biokit, SA) and Gram stain of a $N$ urethral smear were negative.

The patient did not return for follow up nor ज्ञ could he be traced.

\section{Discussion}

The findings in this patient are consistent with굼 a relatively rapid progression of condylomata acuminata into an invasive squamous cell car- $-\frac{\bigcirc}{\Phi}$ cinoma. Taking into account that both HPV and HIV infection in conjunction occur fre-quently in our male patient population it iso nevertheless uncommon to find invasive cancers of the penis. This has been attributed too the shortened life span of individuals infected with HIV in whom HPV may not be able to manifest its full oncogenic potential. ${ }^{4}$ On the other hand, oncogenic HPV DNA sequences in penile carcinomas from Brazilian patients 
were detected less frequently than in cervical neoplasia. ${ }^{5}$ Thus, apart from HIV and HPV infections other factors may be implicated in the development of penile squamous cell carcinoma.

This case report together with the recently reported increase in penile carcinomas in Zimbabwe should alert the medical community to further investigate potentially promoting factors for this type of cancer, and highlights the need for increased surveillance and adequate treatment of these lesions.
1 Zur Hausen H. Papillomaviruses in anogenital cancer as a model to understand the role of viruses in human cancers. Cancer Res 1989;49:4677-81.

2 Frazer IH, Medley G, Crapper RM, Brown TC, Mackay IR. Association between anorectal dysplasia, human papillomavirus and human immunodeficiency virus in homosexual men. Lancet 1986;ii:657-60.

3 Report of the National Cancer Registry. Bulawayo City, Mpilo Hospital, 1996.

4 Paavonen J, Koutsky LA, Kiviat N. Cervical neoplasia and other STD-related genital and anal neoplasias. In: Holmes KK, Mardh P-A, Sparling PF, Wiesner PJ, eds. Sexually transmitted diseases. 2 ed. New York: McGrawHill, 1990;561-92.

5 McCance DJ, Kalache A, Ashdown K, Andrade L, Menezes F, Smith P, et al. Human papillomavirus types 16 and 18 in carcinomas of the penis from Brazil. Int $\mathcal{F}$ Cancer 1986;37:55-9. 